\title{
New insights into early intervention of chronic obstructive pulmonary disease with mild airflow limitation
}

This article was published in the following Dove Press journal: International Journal of Chronic Obstructive Pulmonary Disease

Yilan Sun

Jianying Zhou

Department of Respiratory Diseases, The First Affiliated Hospital, College of Medicine, Zhejiang University, Hangzhou, Zhejiang Province, People's Republic of China

Correspondence: Jianying Zhou

Department of Respiratory Diseases, The First Affiliated Hospital, College of Medicine, Zhejiang University, Hangzhou,

Zhejiang Province 310003, People's

Republic of China

$\mathrm{Tel}+8657187236875$

Fax +8657187236875

Email zjyhz@zju.edu.cn

\begin{abstract}
Chronic obstructive pulmonary disease (COPD) has become one of the major public health problems worldwide due to its high morbidity and mortality. Up until now, COPD is still under-diagnosed and under-treated, especially for mild or moderate patients. It is widely accepted that the majority of patients with COPD are in the early stages, yet this subpopulation is underestimated. In recent years, growing evidence indicates that substantial physiological and clinical abnormalities exist in patients with mild COPD compared with healthy controls. Furthermore, recent studies suggest that pharmacologic intervention in early COPD has the potential to alter clinical outcomes. The main objective of this review is to summarize recent research regarding the heterogeneous pathophysiology, clinical features, and treatment of mild and moderate COPD. We also discuss promising markers of disease progression, which may contribute to the development of precision medicine in early COPD. Keywords: chronic obstructive pulmonary disease, airflow limitation, early intervention, precision medicine
\end{abstract}

\section{Introduction}

Chronic obstructive pulmonary disease (COPD) is a preventable and treatable disease characterized by persistent and progressive airflow limitation. COPD is a leading cause of death in the world, ${ }^{1}$ with high and increasing prevalence both globally and regionally. Based on large-scale epidemiological studies, the number of COPD cases was estimated to be 384 million in 2010, with a global prevalence of $11.7 \% .^{2}$ The COPD burden is projected to increase worldwide in the years to come, owing to both the continuous exposure to COPD risk factors and aging of the population. $^{3}$

Although national and international guidelines for COPD are available, COPD patients, especially mild and moderate patients, are substantially under-diagnosed and under-treated all around the world. ${ }^{4-7}$ Considering the fact that the proportion of mild and moderate COPD patients is very large, ${ }^{4,6-9}$ early diagnosis and intervention, which would prevent and slow disease progression, is as crucial as in other chronic diseases.

This review focuses on three major aspects in mild or moderate COPD: 1) the existence of abundant physiological, spirometric, imaging, and clinical abnormalities; 2) the potential benefits of early diagnosis and intervention; and 3) the distinct patient subgroups, which may be suited for regular pharmacological intervention. 


\section{Definition of early COPD}

The spirometric definition of COPD is the presence of a post-bronchodilator forced expiratory volume in 1 second $\left(\mathrm{FEV}_{1}\right) /$ forced vital capacity $(\mathrm{FVC})$ ratio $<0.7 .^{10}$ However, when the spirometric definition of COPD is based on a fixed ratio, it tends to be overdiagnosed compared with the lower limit of normal criterion, especially in the elderly. ${ }^{11,12}$ In a population-based cohort study, the prevalence of fixed ratio-defined COPD was higher than that of lower limit of normal-defined COPD and this difference was more pronounced with age. ${ }^{11}$ For this review, we define mild COPD as COPD with mild airflow limitation (Global Initiative for Chronic Obstructive Lung Disease (GOLD) stage $1, \mathrm{FEV}_{1} \geq 80 \%$ predicted) and moderate COPD as COPD with moderate airflow limitation (GOLD stage 2, $\mathrm{FEV}_{1} \geq 50 \%$ and $<80 \%$ predicted). Currently, there is no precise definition of early COPD which refers to mild and moderate COPD in this review.

\section{Pathophysiology}

Spirometry is an important diagnosis and classification method based on the severity of airflow limitation in COPD patients. However, spirometric measures of airflow limitation do not perfectly reflect the complex pathologic and physiological disturbances of mild COPD.

The small airways ( $<2 \mathrm{~mm}$ in diameter) are known as the major sites of airway obstruction in COPD. ${ }^{13}$ It has been demonstrated that pathologic abnormalities in the small airways, which include a thickening of the airway wall, infiltration of inflammatory immune cells into the wall tissue, and occlusion of the small airway lumen by inflammatory mucous exudates, are the major reasons for airway obstruction in COPD patients with mild airflow limitation. ${ }^{14}$ Deesomchok et al ${ }^{15}$ observed that the residual volume, functional residual capacity, and total lung capacity were significantly higher than the predicted values in GOLD stage 1, which demonstrated the existence of lung hyperinflation. The presence of an increased residual volume illustrated increased air trapping because of enhanced airway closure during full expiration. ${ }^{15}$

Previous studies showed that a reduction in the lungdiffusing capacity for carbon monoxide (DLCO) was found in the majority of COPD patients with mild airflow limitation compared with controls. ${ }^{15-18}$ Furthermore, approximately $20 \%$ of the GOLD stage 1 subgroup had DLCO $<70 \%$ of that predicted, which may suggest that the surface area of gas exchange was abnormal. ${ }^{15}$ There is increasing evidence that ventilation-perfusion mismatch and an elevated alveolar-arterial oxygen tension gradient emerge in patients with mild COPD. ${ }^{16,19}$ In the study by Rodriguez-Roisin et al, ${ }^{19}$ the alveolar-arterial oxygen tension gradient and ventilation-perfusion imbalance were clearly abnormal in GOLD stage 1, but the changes throughout GOLD stages 1-4 were modest, suggesting that perfusion heterogeneity played a greater role than airflow limitation in the early stage of COPD development.

Significant abnormalities in the pulmonary microvascular blood flow have also been identified in mild COPD. ${ }^{20}$ Similarly, the data from the MESA COPD Study indicated that pulmonary microvascular blood flow decreased in mild COPD in both emphysematous and nonemphysematous lung regions, which may demonstrate an explicit pathological progression procedure from small airway disease. $^{21}$

It is worth noting that smokers who do not meet spirometric criteria for COPD report respiratory symptoms (cough, sputum production). This subpopulation has previously been defined as GOLD stage 0 "at risk" for COPD, ${ }^{22}$ of which $42 \%$ had radiological evidence of emphysema or airway disease. ${ }^{23}$ Meanwhile, extensive small airway inflammation has been described in smokers at risk for COPD, showing increased airway infiltration of polymorphonuclear neutrophils, eosinophils, macrophages, CD4 cells, CD8 cells, and B cells. Moreover, there was no significant difference in the extent of airway inflammation between smokers at risk for COPD and mild COPD. ${ }^{14}$

\section{Lung function}

Although the landmark study by Fletcher and Peto suggested that the rate of decline in $\mathrm{FEV}_{1}$ accelerated with increasing COPD severity, ${ }^{24}$ recent studies showed that the annual $\mathrm{FEV}_{1}$ decline in patients with COPD in GOLD stage 2 was greater than those in GOLD stages 3 and 4. ${ }^{25-27}$ Tantucci and Modina ${ }^{25}$ reported that in large COPD populations the mean decline rate of $\mathrm{FEV}_{1}$ in GOLD stage 2 was between 47 and $79 \mathrm{~mL} /$ year, while the counterpart number in GOLD stages 3 and 4 was between 56 and $59 \mathrm{~mL} /$ year and lower than $35 \mathrm{~mL} /$ year, respectively. Unfortunately, this project did not report sufficient data on the $\mathrm{FEV}_{1}$ decline for GOLD stage 1. However, Bhatt et $\mathrm{al}^{28}$ demonstrated that the rate of $\mathrm{FEV}_{1}$ decline was greatest in mild COPD in a population of current and former smokers. Those with GOLD stage 1 had the most rapid rate of $\mathrm{FEV}_{1}$ decline of $53.8(57.1) \mathrm{mL} /$ 
year compared to $45.6(61.1) \mathrm{mL} /$ year, $31.6(43.6) \mathrm{mL} /$ year, and 5.1 (35.8) $\mathrm{mL} /$ year for GOLD stages 2-4, respectively, showing progressively slower rates of decline with increasing GOLD stages (mean (SD) of the corresponding index). ${ }^{28}$

Hence, the decline in pulmonary function, assessed as expiratory airflow reduction, seems to occur predominantly in the early course of the disease. To postpone the progression of the disease, intervention in the early stages of COPD may be beneficial to patients.

Patients with COPD are generally not homogeneous. In the majority of patients, the course of COPD is usually progressive, as lung function deteriorates over time simultaneously with age-related decline in $\mathrm{FEV}_{1} \cdot{ }^{24}$ Contrary to previous reports, the 3-year ECLIPSE study found that the rate of decline in $\mathrm{FEV}_{1}$ was highly variable in COPD patients, and in more than half of the patients, the rate of decline in $\mathrm{FEV}_{1}$ was no higher than that which has been observed in the healthy control group. These results indicated that COPD was not invariably progressive. ${ }^{27}$ Similarly, another large longitudinal cohort demonstrated that an accelerated decline in $\mathrm{FEV}_{1}$ was not an essential characteristic of COPD. ${ }^{29}$

\section{Imaging}

Computed tomography (CT) of the chest is a standard method of evaluation for patients with COPD. It can also identify a broad range of structural abnormalities including emphysema, airway wall thickening, and gas trapping in mild COPD. ${ }^{23,30}$ In the COPDGene study, $68 \%$ of GOLD stage 1 patients indicated definite emphysema and 67\% airway thickening by means of quantitative CT-scan analysis. ${ }^{23}$ Multidetector CT identified that the number of airways of diameter $2.0-2.5 \mathrm{~mm}$ was reduced in patients with GOLD stage 1 disease compared with control samples $(P=0.001){ }^{31}$

\section{Clinical}

The clinical manifestations of early COPD are variable. ${ }^{32}$ The common symptoms include exertional dyspnea, exercise limitation, chronic cough, and chronic sputum production. ${ }^{9}$ The symptoms are usually minor in patients with mild and moderate COPD, which may be ignored or regarded as the consequences of smoking and aging by both patients and physicians. This may also explain why patients do not seek medical advice until the disease is more advanced. There is evidence from several studies indicating that a significant proportion of patients with mild and moderate COPD suffer from activity-related dyspnea and exercise intolerance. ${ }^{33,34}$ The above symptoms during exercise were linked to increased ventilatory inefficiency and dynamic gas trapping with the progression of the disease. ${ }^{18,35}$ In addition, skeletal muscle dysfunction also impaired physical activity levels and reduced exercise tolerance in patients with mild COPD. ${ }^{36,37}$ However, another group of patients with early COPD, especially those with GOLD stage 1, present no symptoms. Symptomatic patients with mild airflow limitation had a faster decline in $\mathrm{FEV}_{1}$, more respiratory care utilization, and lower quality of life than the healthy control group. Contrarily, asymptomatic patients with mild airflow limitation were similar to the healthy control group regarding $\mathrm{FEV}_{1}$ decline, respiratory care utilization, or quality of life scores. ${ }^{38}$

Although COPD exacerbations occur more frequently in patients with more severe disease, they can be recurrent in milder COPD. In a prospective study, patients with $\mathrm{FEV}_{1}<50 \%$ experienced 3.2 exacerbations per year compared to 2.3 exacerbations per year in patients with $\mathrm{FEV}_{1}$ $\geq 50 \%$. Moreover, $70 \%$ of patients with mild and moderate $\mathrm{COPD}\left(\mathrm{FEV}_{1} \geq 50 \%\right.$ predicted) reported that the frequency of exacerbation was at least once a year. ${ }^{39}$ In fact, a high incidence of unreported exacerbations was found in patients with COPD, particularly those with mild airflow limitation. ${ }^{39,40}$ Unreported exacerbations may not be serious, but still have an important impact on health status. ${ }^{40}$

The major COPD-related comorbidities include cardiovascular disease, diabetes, osteoporosis, depression, anxiety, skeletal muscle dysfunction, and lung cancer. ${ }^{41,42}$ Comorbidities occur in the more advanced stages of the disease (GOLD stage 3 and 4), but can also be present at the early stages of the disease (GOLD stage 1 and 2). ${ }^{32}$ In a long-term longitudinal study, the data showed that the incidence density of lung cancer was greater in patients with milder airflow obstruction than those with more severe airflow obstruction at baseline. Moreover, GOLD stages 1 and 2 were independent risk factors associated with the development of lung cancer. ${ }^{42}$ Omachi et $\mathrm{al}^{43}$ found that patients with mild COPD were at higher risk of depressive symptoms than healthy controls $(26.5 \%$ versus $5.6 \%, P<0.001)$. Comorbidities not only contribute to excess morbidity and mortality, but also influence health outcomes in COPD.

\section{Treatment}

Based on the vast evidence of physiological abnormalities and spirometric, imaging, and clinical features, early 
diagnosis and early intervention in patients with mild and moderate COPD may have beneficial effects on disease progression and clinical outcomes.

Smoking cessation is the most effective intervention for preventing COPD and slowing disease progression. ${ }^{44,45}$ In the Lung Health Study, the results showed that the annual rate of decline in $\mathrm{FEV}_{1}$ among those who quit smoking was only half of the counterpart value for those who continued smoking $(31 \mathrm{~mL} /$ year versus $62 \mathrm{~mL} /$ year) over 4 years in smokers with mildto-moderate COPD. ${ }^{45}$ Moreover, pulmonary rehabilitation is an effective nonpharmacological intervention for all stages of COPD patients including exercise training, education, and behavior change. ${ }^{46} \mathrm{~A}$ systematic review suggested that pulmonary rehabilitation programs significantly improved exercise capacity and health-related quality of life in patients with mild COPD. ${ }^{47}$ Therefore, patients with mild COPD can also benefit from pulmonary rehabilitation.

In addition, pharmacological treatment plays a key role in the intervention for patients with COPD. Major therapeutic efforts and clinical trials have been focused on the severe stages of the disease. However, there is increasing evidence supporting the benefits of regular pharmacological treatment in early COPD. Recent studies suggest that the use of long-acting anticholinergic bronchodilator therapies in mild and moderate COPD patients can reduce the risk and severity of exacerbations, improve health status, and slow disease progression. ${ }^{48,49}$ In a prespecified subgroup analysis of the UPLIFT trial, tiotropium resulted in a lower decline rate of post-bronchodilator $\mathrm{FEV}_{1}$ than placebo (43 $\mathrm{mL} /$ year versus $49 \mathrm{~mL} /$ year, $P=0.024$ ). It also improved health-related quality of life and reduced the risk of exacerbations compared with placebo in patients with GOLD stage 2 disease. ${ }^{48}$ Recently, in another randomized, double-blind, placebo-controlled clinical trial in patients with COPD of GOLD stages 1 or 2 , Zhou et $\mathrm{al}^{49}$ demonstrated that tiotropium significantly increased $\mathrm{FEV}_{1}$ at 24 months and reduced the annual decline in the post-bronchodilator $\mathrm{FEV}_{1}$ $(29 \pm 5 \mathrm{~mL} /$ year versus $51 \pm 6 \mathrm{~mL} /$ year, $P=0.006)$ compared with placebo. Moreover, tiotropium reduced the frequency of acute exacerbations of COPD and improved the life quality of COPD patients compared with placebo. Currently, there is limited evidence that regular treatment benefits patients with mild COPD and further research is needed. It is of significance to explore treatment effects in specific subgroups, by stratifying patients on the basis of clinical, spirometric, or imaging features.

\section{Precision medicine in early COPD}

Due to the fact that patients have different progression rates in terms of lung function decline, it is worthwhile to discuss the question of which patient subgroups are best suited for regular pharmacological intervention in mild and moderate COPD. It is widely accepted that the decline in $\mathrm{FEV}_{1}$ over time is the standard measurement of COPD disease progression. Hence, repeated spirometry can be used to recognize the progression from early to a more severe stage of disease that requires pharmacological intervention. Meanwhile, identification of the clinical, biomarker, spirometric, and imaging characteristics in mild COPD patients with progressive disease is important for providing opportunities for early pharmacological intervention. Several interesting markers associated with lung function decline have been reported.

Chronic mucus hypersecretion (CMH), also known as chronic bronchitis, is common among smokers and is associated with COPD development and progression. In the Copenhagen City Heart Study, Vestbo et $\mathrm{al}^{50}$ found that $\mathrm{CMH}$ was significantly associated with $\mathrm{FEV}_{1}$ decline, especially in men. The data showed that men with $\mathrm{CMH}$ lost an excess $\mathrm{FEV}_{1}$ decline of $22.8 \mathrm{~mL} /$ year compared with men without $\mathrm{CMH}$ after taking age, height, weight change, and smoking into account. COPD exacerbations may also play a role as markers of lung function decline. Dransfield et $\mathrm{al}^{51}$ reported that exacerbations accelerated $\mathrm{FEV}_{1}$ decline in patients with COPD, and the effect was prominent in GOLD stage 1 with an additional $23 \mathrm{~mL} /$ year and $87 \mathrm{~mL} /$ year decline as a result of each exacerbation and severe exacerbation, respectively.

In addition to $F E V_{1}$, other lung function parameters such as the DLCO, a parameter linked to alveolar destruction and possibly small airway disease, may serve as a predictor of lung function decline. Recent data suggested that among smokers with normal spirometry, $22 \%$ of patients in the low DLCO group ( $\mathrm{n}=46$, $<80 \%$ predicted) developed spirometric obstruction $\left(\mathrm{FEV}_{1}: \mathrm{FVC}<0.7\right)$; the counterpart proportion for the normal DLCO group ( $\mathrm{n}=59, \sim 80 \%$ predicted) was only $3 \% .{ }^{52}$ However, the above findings came from smokers with normal spirometry, and thus large-scale studies in patients with mild COPD are required for further confirmation. 
Noninvasive quantitative imaging has provided a novel approach to detect both emphysematous lung destruction and airway remodeling in the peripheral lung, which may assist in identifying the rapid progression in early COPD. Quantitative CT scan found that hyperinflation of the lung was associated with a rapid annual $\mathrm{FEV}_{1}$ decline in smokers with normal $\mathrm{FEV}_{1} \cdot{ }^{53}$ In the study conducted by Bhatt et $\mathrm{al},{ }^{28}$ two new CT metrics were created by parametric response mapping (PRM), a technique that pairs inspiratory and expiratory $\mathrm{CT}$ images to define emphysema (PRMemph) and functional small airway disease (PRMfSAD). They found that both CT-assessed functional small airway disease and emphysema were associated with FEV $_{1}$ decline $(87 \%$ versus $13 \%$ for PRMfSAD and PRMemph in GOLD stage 1/2), and the association with functional small airway disease had the greatest influence in mild and moderate COPD, where the rate of $\mathrm{FEV}_{1}$ decline was the most rapid. ${ }^{28}$

Biomarkers of disease progression in early COPD are unclear. Club cell protein 16 (CC-16) is a protein that is secreted predominantly in the lungs and is believed to have an anti-inflammatory characteristic. The data from the ECLIPSE Study reported that baseline levels of serum $\mathrm{CC}-16$ were associated with accelerated $\mathrm{FEV}_{1}$ decline in COPD patients over 3 years. ${ }^{27} \mathrm{~A}$ similar result was also reported by the Lung Health Study. ${ }^{54}$ Therefore, serum CC-16 may be utilized as a biomarker of disease progression. In addition to CC-16, the plasma pro-surfactant protein B (pro-SFTPB) and the soluble isoform of the receptor for advanced glycation end products (sRAGE) are also reported as potential biomarkers for disease progression. $^{55,56}$

Many attempts have been made to identify genetic markers for predicting lung function decline. In a metaanalysis of large-scale genome-wide association studies, significant associations between $\mathrm{FEV}_{1}$ and numerous single nucleotide polymorphisms were observed by the CHARGE project. These single nucleotide polymorphisms were located around three genes, including INTS12, GSTCD, and NPNT, on chromosome 4q24. Carrying one copy of an implicated reference allele resulted in a lower $\mathrm{FEV}_{1}$ than predicted at a given age. However, the role of genetic factors in predicting disease progression remains speculative. $^{57}$

Whether regular treatment should be considered for patients with mild and moderate COPD may depend on the use of an integrative approach combining these markers with established clinical parameters. Further research is required for markers of disease progression in mild and moderate COPD in order to transfer into clinical practice, and contribute toward personalized medicine in early COPD

\section{Conclusion}

The majority of patients with COPD have mild and moderate airflow limitation. There is substantial evidence that significant physiological, spirometric, imaging, and clinical abnormalities can be detected in mild COPD. Furthermore, recent studies regarding the rate of $\mathrm{FEV}_{1}$ decline in COPD patients demonstrate that faster disease progression occurs in the early stage of COPD. Therefore, early diagnosis and early intervention might be reasonable with the aim of achieving better clinical outcomes in COPD. Exploratory studies suggest that pharmacologic intervention in early COPD may have beneficial effects on ameliorating the decline in lung function so as to improve health status. At the same time, it is well recognized that COPD is a heterogeneous and complex disease that requires sensitive markers to identify disease progression, in order to provide an opportunity for precision medicine. Further research, including clinical trials in distinct patient subgroups, is needed to develop a more evidence-based strategy of personalized intervention in early COPD.

\section{Disclosure}

The authors report no conflicts of interest in this work.

\section{References}

1. Lozano R, Naghavi M, Foreman K, et al. Global and regional mortality from 235 causes of death for 20 age groups in 1990 and 2010: a systematic analysis for the Global Burden of Disease Study 2010. Lancet. 2012; 380(9859): 2095-2128. doi:10.1016/S0140-6736(12) 61728-0

2. Adeloye D, Chua S, Lee C, et al. Global and regional estimates of COPD prevalence: systematic review and meta-analysis. J Glob Health. 2015; 5(2): 020415. doi:10.7189/jogh.05.020415

3. Mathers CD, Loncar D Projections of global mortality and burden of disease from 2002 to 2030. PLoS Med. 2006; 3(11): e442. doi:10.1371/journal.pmed.0030442

4. Miravitlles M, Soriano JB, Garcia-Rio F, et al. Prevalence of COPD in Spain: impact of undiagnosed COPD on quality of life and daily life activities. Thorax. 2009; 64(10): 863-868. doi:10.1136/thx.2009. 115725

5. Lundback BLA, Lindstrom M, Ronmark E, et al. Not 15 but $50 \%$ of smokers develop COPD?-report from the obstructive lung didease in Northern Sweden studies. Respir Med. 2003; 97(2). doi:10.1053/ rmed.2003.1446

6. Bednarek MMJ, Wozniak M, Kuca P, et al. Prevalence, severity and underdiagnosis of COPD in the primary care setting. Thorax. 2008; 63 (5). 402-407 doi:10.1136/thx.2007.085456 
7. Zhong N, Wang C, Yao W, et al. Prevalence of chronic obstructive pulmonary disease in China: a large, population-based survey. Am J Respir Crit Care Med. 2007; 176(8): 753-760. doi:10.1164/ rccm.200612-17490C

8. Buist AS, McBurnie MA, Vollmer WM, et al. International variation in the prevalence of COPD (the BOLD Study): a population-based prevalence study. Lancet. 2007; 370(9589): 741-750. doi:10.1016/ S0140-6736(07)61377-4

9. Mapel DW, Dalal AA, Blanchette CM, et al. Severity of COPD at initial spirometry-confirmed diagnosis: data from medical charts and administrative claims. Int J Chronic Obstr. 2011; 6: 573-581.

10. Vogelmeier CF, Criner GJ, Martinez FJ, et al. Global strategy for the diagnosis, management and prevention of chronic obstructive lung disease 2017 report: GOLD executive summary. Respirology. 2017; 22(3): 575-601. doi:10.1111/resp.13012

11. Karrasch S, Bruske I, Smith MP, et al. What is the impact of different spirometric criteria on the prevalence of spirometrically defined COPD and its comorbidities? Results from the population-based KORA study. Int J Chronic Obstr. 2016; 11: 1881-1894. doi:10.2147/COPD.S104529

12. Guder G, Brenner S, Angermann CE, et al. "GOLD or lower limit of normal definition? A comparison with expert-based diagnosis of chronic obstructive pulmonary disease in a prospective cohort-study“. Respir Res. 2012; 13(1): 13. doi:10.1186/1465-9921-13-13

13. Hogg JC, Macklem PT, Thurlbeck WM Site and nature of airway obstruction in chronic obstructive lung disease. $N$ Engl J Med. 1968; 278(25): 1355-1360. doi:10.1056/NEJM196806202782501

14. Hogg JC, Chu F, Utokaparch S, et al. The nature of small-airway obstruction in chronic obstructive pulmonary disease. $N$ Engl J Med. 2004; 350(26): 2645-2653. doi:10.1056/NEJMoa032158

15. Deesomchok A, Webb KA, Forkert L, et al. Lung hyperinflation and its reversibility in patients with airway obstruction of varying severity. Copd. 2010; 7(6): 428-437. doi:10.3109/15412555.2010.528087

16. Elbehairy AF, Ciavaglia CE, Webb KA, et al. Pulmonary gas exchange abnormalities in mild chronic obstructive pulmonary disease. implications for dyspnea and exercise intolerance. Am J Respir Crit Care Med. 2015; 191(12): 1384-1394. doi:10.1164/ rccm.201501-01570C

17. Guenette JA, Chin RC, Cheng S, et al. Mechanisms of exercise intolerance in global initiative for chronic obstructive lung disease grade 1 COPD. Eur Respir J. 2014; 44(5): 1177-1187. doi:10.1183/ 09031936.00034714

18. Ofir D, Laveneziana P, Webb KA, et al. Mechanisms of dyspnea during cycle exercise in symptomatic patients with GOLD stage I chronic obstructive pulmonary disease. Am J Respir Crit Care Med. 2008; 177(6): 622-629. doi:10.1164/rccm.200707-1064OC

19. Rodriguez-Roisin R, Drakulovic M, Rodriguez DA, et al. Ventilationperfusion imbalance and chronic obstructive pulmonary disease staging severity. J Appl Physiol (1985). 2009; 106(6): 1902-1908. doi:10.1152/japplphysiol.00085.2009

20. Peinado VI, Pizarro S, Barbera JA Pulmonary vascular involvement in COPD. Chest. 2008; 134(4): 808-814. doi:10.1378/chest.08-0820

21. Hueper K, Vogel-Claussen J, Parikh MA, et al. Pulmonary microvascular blood flow in mild chronic obstructive pulmonary disease and emphysema. The MESA COPD Study. Am J Respir Crit Care Med. 2015; 192(5): 570-580. doi:10.1164/rccm.201411-2120OC

22. Pauwels RA, Buist AS, Calverley PM, et al. Global strategy for the diagnosis, management, and prevention of chronic obstructive pulmonary disease. NHLBI/WHO Global Initiative for Chronic Obstructive Lung Disease (GOLD) Workshop summary. Am $J$ Respir Crit Care Med. 2001; 163(5): 1256-1276. doi:10.1164/ ajrccm.163.5.2101039

23. Regan EA, Lynch DA, Curran-Everett D, et al. Clinical and radiologic disease in smokers with normal spirometry. JAMA Intern Med. 2015; 175(9): 1539-1549. doi:10.1001/jamainternmed.2015. 2735
24. Fletcher C, Peto R The natural history of chronic airflow obstruction. Br Med J. 1977; 1(6077): 1645-1648.

25. Tantucci C, Modina D Lung function decline in COPD. Int J Chron Obstruct Pulmon Dis. 2012; 7: 95-99. doi:10.2147/COPD.S27480

26. Jenkins CR, Jones PW, Calverley PMA, et al. Efficacy of salmeterol/ fluticasone propionate by GOLD stage of chronic obstructive pulmonary disease: analysis from the randomised, placebo-controlled TORCH study. Resp Res. 2009; 10:59.

27. Vestbo J, Edwards LD, Scanlon PD, et al. Changes in forced expiratory volume in 1 second over time in COPD. $N$ Engl J Med. 2011; 365(13): 1184-1192. doi:10.1056/NEJMoa1105482

28. Bhatt SP, Soler X, Wang X, et al. Association between functional small airway disease and FEV1 decline in chronic obstructive pulmonary disease. Am J Resp Crit Care. 2016; 194(2): 178-184. doi:10.1164/rccm.201511-22190C

29. Lange P, Celli B, Agusti A, et al. Lung-function trajectories leading to chronic obstructive pulmonary disease. New Engl J Med. 2015; 373(2): 111-122. doi:10.1056/NEJMoa1411532

30. Schroeder JD, McKenzie AS, Zach JA, et al. Relationships between airflow obstruction and quantitative CT measurements of emphysema, air trapping, and airways in subjects with and without chronic obstructive pulmonary disease. Am J Roentgenol. 2013; 201(3): W460-W470. doi:10.2214/AJR.12.10102

31. McDonough JE, Yuan R, Suzuki M, et al. Small-airway obstruction and emphysema in chronic obstructive pulmonary disease. New Engl $J$ Med. 2011; 365(17): 1567-1575. doi:10.1056/NEJMoa1106955

32. Agusti A, Calverley PMA, Celli B, et al. Characterisation of COPD heterogeneity in the ECLIPSE cohort. Resp Res. 2010; 11:122.

33. Steuten LMCE, Vrijhoef HJ, Wouters EF COPD as a multicomponent disease: inventory of dyspnoea, underweight, obesity and fat free mass depletion in primary care. Prim Care Respir $J$ 2006; 15(2). doi:10.1016/j.pcrj.2005.09.001

34. Guenette JA, Jensen D, Webb KA, et al. Sex differences in exertional dyspnea in patients with mild COPD: physiological mechanisms. Respir Physiol Neurobiol. 2011; 177(3): 218-227. doi:10.1016/j. resp.2011.04.011

35. O`Donnell DE, Laveneziana P, Webb K, et al. Chronic obstructive pulmonary disease: clinical integrative physiology. Clin Chest Med. 2014; 35(1):51. doi:10.1016/j.ccm.2013.09.008

36. Shrikrishna D, Patel M, Tanner RJ, et al. Quadriceps wasting and physical inactivity in patients with COPD. Eur Respir J. 2012; 40(5): 1115-1122. doi:10.1183/09031936.00170111

37. Seymour JM, Spruit MA, Hopkinson NS, et al. The prevalence of quadriceps weakness in COPD and the relationship with disease severity. Eur Respir J. 2010; 36(1): 81-88. doi:10.1183/ 09031936.00104909

38. Bridevaux PO, Gerbase MW, Probst-Hensch NM, et al. Long-term decline in lung function, utilisation of care and quality of life in modified GOLD stage 1 COPD. Thorax. 2008; 63(9): 768-774. doi:10.1136/thx.2007.093724

39. O‘Reilly JF, Williams AE, Holt K, et al. Defining COPD exacerbations: impact on estimation of incidence and burden in primary care. Prim Care Respir J. 2006; 15(6): 346-353. doi:10.1016/j. pcrj.2006.08.009

40. Langsetmo L, Platt RW, Ernst P, et al. Underreporting exacerbation of chronic obstructive pulmonary disease in a longitudinal cohort. $\mathrm{Am}$ J Respir Crit Care Med. 2008; 177(4): 396-401. doi:10.1164/ rccm.200708-12900C

41. Decramer M, Rennard S, Troosters T, et al. COPD as a lung disease with systemic consequences - clinical impact, mechanisms, and potential for early intervention. Copd-J Chron Obstruct Pulmon Dis. 2008; 5(4): 235-256. doi:10.1080/15412550802237531

42. de Torres JP, Marin JM, Casanova C, et al. Lung cancer in patients with chronic obstructive pulmonary disease incidence and predicting factors. Am J Resp Crit Care. 2011; 184(8): 913-919. doi:10.1164/ rccm.201103-0430OC 
43. Omachi TA, Katz PP, Yelin EH, et al. Depression and health-related quality of life in chronic obstructive pulmonary disease. Am J Med. 2009; 122(8). 778.e9-778.e15 doi:10.1016/j. amjmed.2009.01.036

44. Anthonisen NR, Connett JE, Murray RP Smoking and lung function of Lung Health Study participants after 11 years. Am J Respir Crit Care Med. 2002; 166(5): 675-679. doi:10.1164/ recm.2112096

45. Scanlon PD, Connett JE, Waller LA, et al. Smoking cessation and lung function in mild-to-moderate chronic obstructive pulmonary disease. The Lung Health Study. Am J Respir Crit Care Med. 2000; 161(2 Pt 1): 381-390. doi:10.1164/ajrccm.161. 2.9901044

46. Corhay JL, Dang DN, Van Cauwenberge H, et al. Pulmonary rehabilitation and COPD: providing patients a good environment for optimizing therapy. Int J Chron Obstruct Pulmon Dis. 2014; 9: 27-39. doi:10.2147/COPD.S52012

47. Jacome C, Marques A Pulmonary rehabilitation for mild COPD: a systematic review. Respir Care. 2014; 59(4): 588-594. doi:10.4187/respcare.02742

48. Decramer M, Celli B, Kesten S, et al. Effect of tiotropium on outcomes in patients with moderate chronic obstructive pulmonary disease (UPLIFT): a prespecified subgroup analysis of a randomised controlled trial. Lancet. 2009; 374(9696): 1171-1178. doi:10.1016/ S0140-6736(09)61298-8

49. Zhou Y, Zhong NS, Li X, et al. Tiotropium in early-stage chronic obstructive pulmonary disease. $N$ Engl J Med. 2017; 377(10): 923-935. doi:10.1056/NEJMoa1700228
50. Vestbo J, Prescott E, Lange P Association of chronic mucus hypersecretion with FEV1 decline and chronic obstructive pulmonary disease morbidity. Copenhagen City Heart Study Group. Am J Respir Crit Care Med. 1996; 153(5): 1530-1535. doi:10.1164/ajrccm.153.5.8630597

51. Dransfield MT, Kunisaki KM, Strand MJ, et al. Acute exacerbations and lung function loss in smokers with and without chronic obstructive pulmonary disease. Am J Resp Crit Care. 2017; 195(3): 324-330.

52. Harvey BG, Strulovici-Barel Y, Kaner RJ, et al. Risk of COPD with obstruction in active smokers with normal spirometry and reduced diffusion capacity. Eur Respir J. 2015; 46(6): 1589-1597. doi:10.1183/13993003.02377-2014

53. Yuan R, Hogg JC, Pare PD, et al. Prediction of the rate of decline in FEV1 in smokers using quantitative computed tomography. Thorax. 2009; 64(11): 944-949. doi:10.1136/thx.2008.112433

54. Park HY, Churg A, Wright JL, et al. Club cell protein 16 and disease progression in chronic obstructive pulmonary disease. Am J Respir Crit Care Med. 2013; 188(12): 1413-1419. doi:10.1164/ rccm.201305-0892OC

55. Leung JM, Mayo J, Tan W, et al. the Pan-Canadian Early Lung Cancer Study Group. Plasma pro-surfactant protein B and lung function decline in smokers. Eur Respir J. 2015; 45: 1037-1045.56. doi:10.1183/09031936.00184214

56. Smith DJ, Yerkovich ST, Towers MA, et al. Reduced soluble receptor for advanced glycation end-products in COPD. Eur Respir J. 2011; 37(3): 516-522 doi:10.1183/09031936.00029310

57. Hancock DB, Eijgelsheim M, Wilk JB, et al. Meta-analyses of genome-wide association studies identify multiple loci associated with pulmonary function. Nat Genet. 2010; 42(1): 45-52. doi:10.1038/ng.500

International Journal of Chronic Obstructive Pulmonary Disease

Dovepress

\section{Publish your work in this journal}

The International Journal of COPD is an international, peer-reviewed journal of therapeutics and pharmacology focusing on concise rapid reporting of clinical studies and reviews in COPD. Special focus is given to the pathophysiological processes underlying the disease, intervention programs, patient focused education, and self managemen protocols. This journal is indexed on PubMed Central, MedLine and CAS. The manuscript management system is completely online and includes a very quick and fair peer-review system, which is all easy to use. Visit http://www.dovepress.com/testimonials.php to read real quotes from published authors. 